\title{
Material values: A study of some antecedents and consequences
}

\author{
Valores materiales: un estudio de algunos antecedentes y consecuencias \\ Rogelio Puente Díaz ${ }^{\mathrm{a}, *}$, Judith Cavazos Arroyo ${ }^{\mathrm{b}}$ \\ ${ }^{a}$ Universidad Anáhuac, Mexico \\ ${ }^{\mathrm{b}}$ Universidad Popular Autónoma del Estado de Puebla, Mexico
}

Received 14 August 2015; accepted 4 March 2016

Available online 10 August 2017

\begin{abstract}
Two studies were conducted to analyze some antecedents and consequences of holding material values among college students from Mexico. Participants completed a battery of questionnaires measuring social comparison orientation, autonomy support, materialism, life satisfaction, positive and negative affect, and job preferences. Results showed that social comparison was a robust predictor of materialism in both studies. Materialism was related to lower levels of positive affect and life satisfaction and to higher levels of negative affect. Materialism was also related to a preference for jobs that pay more money at the expense of working longer hours or doing more routine tasks. The implications of the results were discussed.

(C) 2017 Universidad Nacional Autónoma de México, Facultad de Contaduría y Administración. This is an open access article under the CC BY-NC-ND license (http://creativecommons.org/licenses/by-nc-nd/4.0/).
\end{abstract}

Keywords: Material values; Consumer behavior; Subjective well-being

JEL classification: M31; I31; J00

\section{Resumen}

Se realizaron dos estudios para analizar algunos antecedentes y consecuencias de la presencia de valores materiales entre estudiantes universitarios en México. Los participantes completaron una batería de cuestionarios que miden orientación a la comparación social, apoyo a la autonomía, materialismo, satisfacción con la vida, afecto positivo y negativo, y preferencias laborales. Los resultados mostraron que la comparación social fue un predictor robusto del materialismo en ambos estudios. El materialismo se relacionó con los

\footnotetext{
* Corresponding author.

E-mail address: rogelio.puente@anahuac.mx (R. Puente Díaz).

Peer Review under the responsibility of Universidad Nacional Autónoma de México.
} 
niveles más bajos de afecto positivo y satisfacción con la vida y con los niveles más altos de afecto negativo. El materialismo también se relacionó con una preferencia por los trabajos que pagan más dinero a costa de trabajar más horas o hacer las tareas más rutinarias. Las implicaciones de los resultados fueron discutidas. (C) 2017 Universidad Nacional Autónoma de México, Facultad de Contaduría y Administración. Este es un artículo Open Access bajo la licencia CC BY-NC-ND (http://creativecommons.org/licenses/by-nc-nd/4.0/).

Palabras clave: Valores materiales; Comportamiento del consumidor; Bienestar subjetivo Códigos JEL: M31; I31; J00

\section{Material values: an exploration of some antecedents and consequences}

Values play a central role since they influence the goals and life styles people choose and the emotions they feel (Schwartz, 2005). Values also play an important role in consumer research (Pepper, Jackson, \& Uzzell, 2009). Specifically, investigators, interested in understanding the social psychology of consumer behavior, have turned their attention to the examination of some antecedents and consequences of holding material values. Examining the antecedents and consequences of holding material values seems particularly relevant given the economic uncertain times we are living in. Consequently, the present investigation, using the theory of material values as guiding framework (Kasser, 2002), attempts to make a contribution by: (1) examining the role of social comparison orientation, and autonomy support as antecedents of material values and also (2) assessing the affective, cognitive, and behavioral consequences of holding material values. In order to accomplish this goal, we first review the relevant literature on values.

\section{Material values}

Even though there are different values that individuals might hold, material values seem particularly relevant for understanding consumer behavior (Grougiou \& Moschis, 2015). Material values give importance to the acquisition of material goods and possessions (Richins \& Dawson, 1992) and consumer style (Zampieri et al., 2012). The theory of materialistic values (Kasser, 2002) seeks to answer two important questions: (1) what drives individuals to value material possessions and (2) what are some of the consequences of holding material values. Even though consumer researchers (Kasser, 2002; Richins \& Dawson, 1992) have warned us about the widespread endorsement of material values, we would expect consumers to have significant variation in their levels of endorsement of material values and this is precisely one of the things that we would like to explain. That is, we would like to identify which variables act as antecedents of materialism.

\section{Antecedents: social comparison and autonomy support}

The theory of materialistic values (Kasser, 2002) suggests that individuals might come to endorse material values for two main reasons: (1) social models endorsing the importance of material possessions, a socialization process and (2) lack of fulfillment of the basic psychological needs for autonomy, relatedness and competence, which creates feelings of insecurity. Both factors can act as independent antecedents or in conjunction. In the present investigation, we analyze the role of social comparison orientation (study 1 and 2) and autonomy support (study 2) as proxies 
of the two factors suggested by the theory of material values and examine their role as possible antecedents of materialism.

According to social comparison theory (Festinger, 1954), people have the drive to evaluate themselves (self-evaluation) by comparing their opinions and abilities with others. Social comparison is such a common and central process that can occur automatically, without conscious intent (Mussweiler, 2007). Our argument is that consumers also use social comparisons to learn and evaluate what is desirable in terms of material possessions. Consumer researchers extend social comparison theory to include the comparison of material possessions, suggesting that material possessions provide individuals with a source of information about what is valuable and desirable and also help communicate their social standing in relation to others. Thus, individuals might be prone to not only compare their opinions and abilities with others, but also their material possessions.

With regard to the role of social comparison in learning what material possessions are desirable, Duesenberry (1949) proposes the term demonstration effect. Demonstration effect is the idea that individuals compare their consumption habits with others. Thus, what is desirable is not only a function of the intrinsic attributes of a material possession or a reflection of one's true preferences, but also a function of what significant and similar others possess. What this shows is the interdependence of consumer preferences, lending evidence to the important role of social comparison as a source of information for consumers. Through social comparisons, consumers learn what is valuable and desirable.

With regard to social standing, there is evidence suggesting that individuals compare their own material possessions with those owned by significant others to ascertain their social status (Saunders, 2001). Humans are equipped to notice and pay close attention to social status and rank (Hill \& Buss, 2008). It follows then that if material possessions are reliable indicators of social rank, then individuals would have the tendency to compare what they have in relation to others.

Even though the proposed relationship between the endorsement of material values and social comparison appears to be consistent across cultures, this relationship might be particularly strong for cultures where the self is defined interdependently, collectivistic cultures. For example in the Chinese culture, social comparison of material possessions serves the purpose of positioning individuals in the social hierarchy, being therefore encouraged (Wong \& Ahuvia, 1998). Similarly, a study in Japan found that social comparison was positively related with a higher desire for more possessions and higher consumption intentions (Ogden \& Venkat, 2001). These two crosscultural investigations, however, had some limitations. Whereas Chine and Japanese cultures can be considered collectivistic in nature, they represent a type of collectivism based on humility, referred to as Confucian-based collectivism. Conversely, Latin-American cultures such as Brazil or Mexico endorse a type of collectivism based on honor (Uskul, Oyserman, \& Schwarz, 2010; Zampieri et al., 2012). Thus, investigations with participants from collectivistic cultures of honor would allow us to corroborate the importance of social comparisons in consumption related values such as materialism. There is evidence already about the importance of significant others in collectivistic cultures of honor (Diaz-Guerrero, 2008). To test the role of social comparison as an antecedent of material values, the following hypothesis is formulated:

1. Social comparison orientation would have a positive effect on materialism.

As mentioned earlier, the theory of materialistic values (Kasser, 2002) also proposes the lack of satisfaction of basic psychological needs as an antecedent of materialism. Self-determination theory suggests that humans share three psychological needs that should be satisfied in order to have optimal functioning (Ryan \& Deci, 2002). One of these needs, the need for autonomy, has 
been examined and found to be an antecedent of material values (Kasser, Ryan, Couchman, \& Sheldon, 2004). Specifically, the theory of material values suggests that when individuals feel that they do not have an environment supportive of their autonomy, they might orient toward material values in order to compensate for the lack of autonomy support (Kasser, 2002). Consequently, low levels of autonomy support should increase the likelihood of endorsing material values. The following hypothesis is formulated:

2. Autonomy support would have a negative effect on materialism.

In sum, we attempt to test the role of social comparison orientation as an antecedent of materialism (study 1) and the role of social comparison orientation and autonomy support as antecedents of materialism (study 2). We now turn our attention to some of the possible consequences of holding material values.

\section{Consequences: affective, cognitive and behavioral}

The importance of values lies in that individual differences in the endorsement materialism are expected to lead to different cognitive, affective and behavioral outcomes (Kasser, 2002). For example, materialistic values affect how individuals related to possessions, work and spend money on themselves and friends (Deckop, Jurkiewicz, \& Giancalone, 2010; Roberts, 2011). Among the different outcomes that materialism is likely to influence, consumers' subjective well-being is particularly relevant.

Researchers have suggested that subjective well-being has three components: cognitive assessment of life satisfaction, positive, and negative affect (Diener, 1984). Across different investigations, materialism seems to exert a negative effect on subjective well-being (Burroughs \& Rindfleisch, 2002; Dittmar, Bond, Hurst, \& Kasser, 2014). However, in our opinion, many of these investigations have had limitations. First, several investigations have not conceptualized well-being as a three component psychological construct (Burroughs \& Rindfleisch, 2002). That is, investigations have focused mainly on assessing the impact of materialism on judgments of general and domain specific satisfaction, paying less attention to the influence of materialism on positive and negative affect. Second, most investigations have been conducted with participants from individualistic cultures (Burroughs \& Rindfleisch, 2002), limiting our ability to generalize results to other cultures. For example in collectivistic cultures of honor such as Mexico, reputation and the opinion of others are two important factors that could potentially influence materialism and its effect on subjective well-being (see Podoshen, Li \& Zhang, 2010; Workman \& Lee, 2010; Xiao \& Kim, 2009 for recent exceptions examining materialism among members from Confucian based collective cultures such as China and Korea). The following hypotheses are formulated:

3a. Materialism would have a negative effect on satisfaction with life.

3b. Materialism would have a negative effect on positive affect.

3c. Materialism would have a positive effect on negative affect.

Our current economic and social systems encourage the acquisition of material possessions (Kasser, 2002). Yet, most people have limited financial resources. Thus, the desire toward acquiring material possessions should have multiple consequences in different areas of people's lives. There is evidence suggesting that material values are likely to influence different consumption related outcomes (Deckop, Jurkiewicz, \& Giancalone, 2010). However, we suggest that their impact goes beyond traditional consumption variables and include relevant outcomes such as a preference for particular jobs that provide more monetary resources. 
Some investigations have shown that highly materialistic individuals report feelings of external pressure to achieve goals consistent with materialistic values (Sheldon \& Kasser, 2001), including the desire to make more money (Lemrová, Reiterová, Fatenová, Lemr, \& Tang, 2014; Srivastava, Locke, \& Borrol, 2001) and the idea that financial success should be a fundamental aspiration in their value structure (Grouzet et al., 2005). However, these investigations did not actually examine a tradeoff that is inherent in some financial decisions: A desire to make more money at the expense of making some sacrifices. In other words, it is likely that most people would want to earn more money, yet it is the tradeoff between more money and some sacrifices what we consider to be of special interest. In order to assess this, we study if material values are capable of predicting preferences for jobs requiring longer hours or with less diversity of tasks in order to make more money and test the following hypothesis:

4. Materialism would increase the probability of choosing jobs with higher salaries but longer working days or more routine tasks.

\section{Implications}

The examination of the antecedents and consequences of material values might have implications for marketing and human resources. First, marketing makes the assumption that the satisfaction of consumer needs is the driving force behind the development of products and services (Kotler \& Keller, 2013). Yet as suggested by our literature review, when individuals emphasize the acquisition of material values, they might end up being less satisfied, which represents an interesting paradox for marketers. Second, human resources departments seek to hire the best possible employees for their organizations. Knowing that material values might potentially influence the attractiveness of different job offers, human resources personnel might be able to infer the job orientation of individuals, seeking more extrinsic or intrinsic job outcomes (Hall \& Las Heras, 2012) and its possible consequences.

In sum, the purpose of the present investigation is twofold. First, we test the role of social comparison orientation and autonomy support as antecedents of material values. Second, we examine the affective, positive and negative affect, cognitive, life satisfaction, and behavioral consequences, choosing job offers with higher (lower) salaries at the expense of longer (shorter) working days and routine (diverse) tasks, of holding material values.

\section{Overview of studies}

Two studies were conducted test some antecedents and consequences of holding material values. Study 1 examined the role of social comparison orientation as an antecedent of material values and the influence of material values on satisfaction with life, positive and negative affect, and job preferences. Study 2 examined the role of social comparison orientation and autonomy support as antecedents of material values and also the influence of material values on positive and negative affect.

\section{Participants and procedure study 1}

Participants were 386 (247 females and 139 males) college students from two private universities in the Mexico City area (Universidad Anáhuac) and Puebla (Universidad Popular Autónoma 
del Estado de Puebla). The mean age was $22.47(\mathrm{SD}=2.45)$. Students received extra credit for their participation.

Participants completed the questionnaires in small groups of two or three. The questionnaires took between 15 and 20 min to complete. All participants were thanked and debriefed after their participation. The present investigation obtained the approval from the institutional human subjects committee.

\section{Measures}

The Satisfaction with Life Scale (SWLS) (Diener, Emmons, Larsen, \& Griffin, 1985). The SWLS is a five-item questionnaire designed to measure satisfaction with life. The questionnaire uses a Likert-type scale and total scores range from 5 to 35 . The scale showed adequate psychometric properties for scientific research (e.g., significant loadings and a coefficient of internal consistency of .84) and previous research has also shown acceptable properties with Spanish speaking participants (Vazquez, Duque, \& Hervas, 2013).

The Scale of Positive and Negative Experience (SPANE) (Diener et al., 2009). The SPANE is a twelve-item questionnaire that includes six items to assess positive feelings and six items to assess negative feelings. Each item is scored on a scale ranging from 1 to 5 , where 1 represents "very rarely or never" and 5 represents "very often or always." The positive and negative scales are scored separately. The scale showed adequate psychometric properties for scientific research (e.g., significant loadings and coefficients of internal consistency above .67). Similar scales have been validated with Spanish speaking participants (e.g., Moriondo, De Palma, Medrano, \& Murillo, 2012).

The Material Value Scale (MVS) (Richins, 2004). We used the abbreviated nine-item measure of materialistic values. Each item is scored on a scale ranging from 1 to 5, where 1 represents "strongly disagree" and 5 represents "strongly agree." The scale possesses good psychometric properties, especially when it is used to measure materialism at the general level. The scale showed adequate psychometric properties for scientific research (e.g., significant loadings and a coefficient of internal consistency of .78) and has shown adequate psychometric properties with Spanish speaking participants as well (Puente-Díaz \& Cavazos-Arroyo, 2015).

The Iowa-Netherlands Comparison Orientation Measure (INCOM) (Gibbons \& Buunk, 1999). The INCOM is an eleven-item questionnaire designed to assess individual differences in social comparison orientation. Each item is scored on a scale ranging from 1 to 5, where 1 represents "strongly disagree" and 5 represents "strongly agree." Higher scores present higher levels of social comparison orientation. The scale showed adequate psychometric properties for scientific research (e.g., significant loadings and a coefficient of internal consistency of .79) and has been validated with Spanish speaking participants (e.g., Buunk, Belmonte, Peiró, Zurriaga, \& Gibbons, 2005).

Decision making task. We presented participants with one of two decision making tasks. In one task, participants had to choose between a job with a monthly salary of 1300 American dollars and routine tasks vs. 1000 American dollars and diverse tasks. Similarly, the second decision making tasks involved two options: a job with a monthly salary of 1300 American dollars and 10-h working days vs. 1000 American dollars and 8-h working days. Participants were only exposed, randomly, to one of the two tasks. Both tasks involved a tradeoff between making more money and either having a less challenging or boring job (routine task) or working longer hours. This decision making task was designed to test whether material values influence choices that are somewhat related but at the same time independent of consumption. 


\section{Results study 1}

We used Structural Equation Modeling (SEM) with LISREL 9.1 to test our hypotheses. In order to assess the robustness of the model, we used a combination of absolute and incremental fit index. Thus, we report the $\chi^{2}$, Root Mean Square Error of Approximation (RMSEA), and the Incremental Fit Index (IFI) for each of the analysis conducted. We used the cutoff scores of RMSEA $<.08$ and IFI $>.90$ as the minimum acceptable levels of model fit (West, Taylor, \& Wu, 2012).

We first examined the measurement model for the latent variables materialism, social comparison, satisfaction with life, and positive and negative affect. Results showed that the model fit was adequate $\chi^{2}=1137.16, p=.00(\mathrm{df}=617)$, RMSEA $=.05$ and IFI $=.94$. Examination of individual parameters revealed that all factor loadings were significant and in the expected direction. Thus, we decided to keep this measurement model and proceeded to test the structural model.

Results showed that the model fit was adequate $\chi^{2}=1207.57, p=.00(\mathrm{df}=622), \mathrm{RMSEA}=.05$ and $\mathrm{IFI}=.93$. Examination of the individual parameters revealed that social comparison had significant positive effect on materialism, $\gamma=.43, p<.05$. Thus, hypothesis 1 was supported. Regarding the consequences of holding material values, we found a significant negative effect of materialism on satisfaction with life and positive affect, $\beta=-.16, p<.05 ; \beta=-.23, p<.05$, respectively, while controlling for the effect of positive affect on satisfaction with life, supporting hypothesis $3 \mathrm{a}$ and $3 \mathrm{~b}$. Lastly, results also showed a significant positive effect of materialism on negative affect, $\beta=.32, p<.05$, supporting hypothesis $3 \mathrm{c}$ (see Fig. 1 for the complete model). Squared multiple correlations for the endogenous variables were, respectively, materialism (0.18), satisfaction with life (0.33), positive affect $(0.05)$, and negative affect (0.10).

Since we were interested in examining the effect of materialistic values and social comparison on the probability of choosing a job with a higher salary and longer hours or higher salary and less diverse activities, we conducted two logistic regression analyses. Job offers with lower salaries were coded as 0 and offers with higher salaries were coded as 1 . Consequently, the logistic regression analyses allowed us to examine the influence of materialism on the probability of choosing job offers with higher salaries but longer hours or less diverse activities. Descriptive statistics showed that $44 \%$ of participants chose the job with a higher salary and routine activities, whereas $60 \%$ selected the job with higher salary or longer hours (10 vs. 8). The results showed that materialism had positive effect on the probability of choosing both job offers with a higher salary and more routine activities and longer hours $(\beta=.56, p<.05, \exp \beta=1.75 ; \beta=.66$, $p<.05, \exp \beta=1.94$, respectively). The effects of social comparison were not significant in any of the two analyses $(\beta=.13, p>.05 ; \beta=-.04, p>.05$, respectively). Thus, hypothesis 4 was supported.

\section{Brief discussion study 1}

Our results showed that social comparison had a significant, positive effect on materialism. Results also showed that materialism influenced affective, cognitive and behavioral outcomes. The significant effect of social comparison on materialism was encouraging, yet we believe it was necessary to conduct an additional study to further validate the findings obtained in study 1 and analyze autonomy support as another antecedent of materialism. 


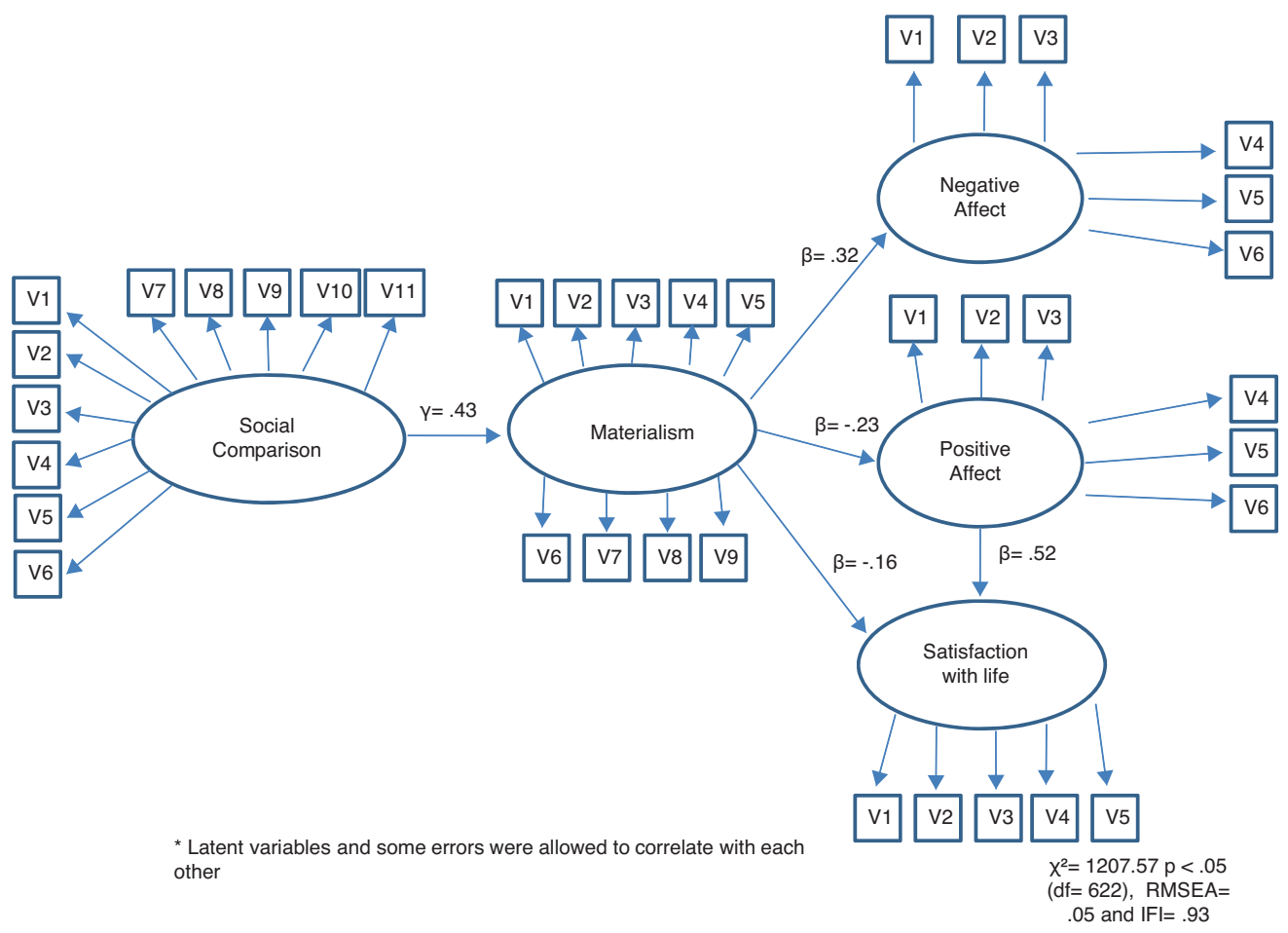

Figure 1. Structural equation model for study 1.

Source: Authors.

\section{Participants and procedure study 2}

Participants were 339 (194 females and 145 males) college students from two private universities in the Mexico City area (Universidad Anáhuac) and Puebla (Universidad Popular Autónoma del Estado de Puebla). The mean age was $21.54(\mathrm{SD}=2.61)$. Students received extra credit for their participation.

Participants completed the questionnaires in small groups of two or three. The questionnaires took between 15 and 20 min to complete. All participants were thanked and debriefed after their participation. The present investigation obtained the approval from the institutional human subjects committee.

\section{Measures}

For study 2, the same questionnaires, as in study 1, measuring materialism, social comparison, and positive and negative affect were used. Consistent with study 1 , the coefficients of internal consistency were acceptable: materialism (.79), social comparison (.79), positive affect (.83) and negative affect (.71). The only new questionnaire was:

General Need Satisfaction Scale (Gagné, 2003). This scale was adapted based on SelfDetermination Theory by Gagné (2003) and uses 21 items to measure need satisfaction. Respondents indicated on a scale from 1 (not true at all) to 7 (definitely true) the extent to which the psychological needs of autonomy, relatedness, and competence are generally satisfied 


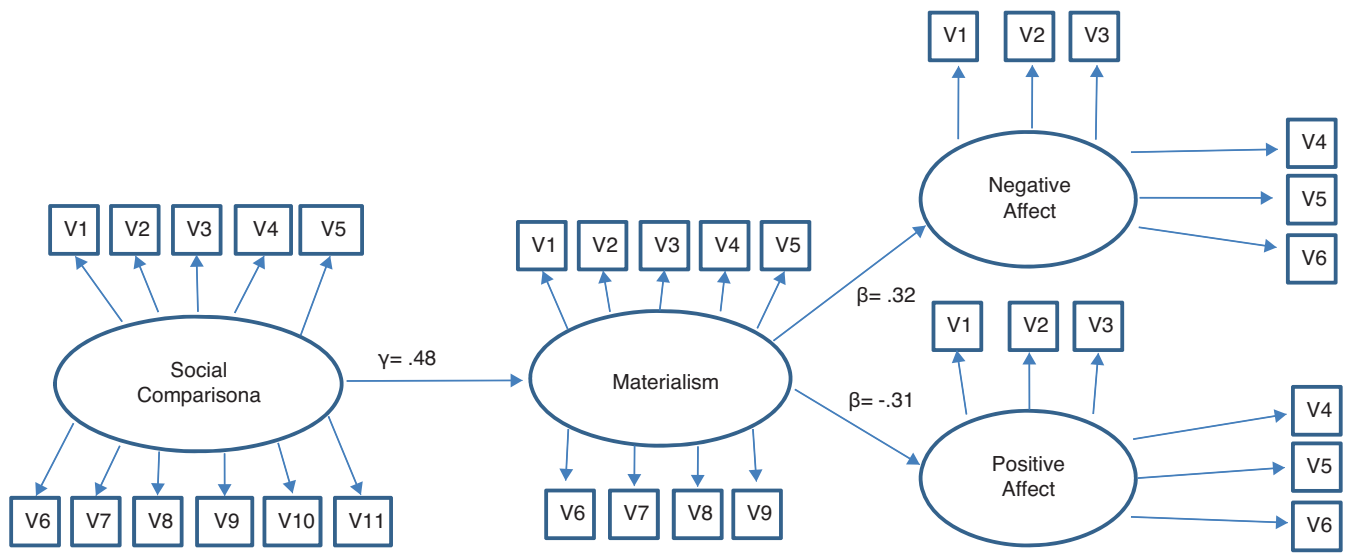

$$
\begin{gathered}
\mathrm{X}^{2}=932.67 \mathrm{p}<.05 \\
(\mathrm{df}=420), \mathrm{RMSEA}= \\
.06 \text { and } \mathrm{IFI}=.92
\end{gathered}
$$

Figure 2. Structural equation model for Study 2.

Source: Authors.

in their lives. For the purpose of our investigation, we only measured autonomy support. The scale showed adequate psychometric properties (e.g., significant loadings and a coefficient of internal consistency of .65) and has been validated with Spanish speaking participants (e.g., Domínguez, Martín, Martín-Albo, Núñez, \& León, 2010).

\section{Results study 2}

We first examined the measurement model for the latent variables social comparison, materialism, autonomy support and positive and negative affect. Results showed that the model fit was adequate $\chi^{2}=1593.48, p=.00(\mathrm{df}=645)$, RMSEA $=.07$ and $\mathrm{IFI}=.91$. Examination of individual parameters revealed that all factor loadings were significant and in the expected direction. Thus, we decided to keep this measurement model and proceed to test the structural model.

Results showed that the model fit was barely adequate $\chi^{2}=1667.99, p=.00 \quad(\mathrm{df}=649)$, RMSEA $=.07$ and IFI $=.90$. Examination of the individual parameters showed that autonomy support did not have a significant effect on materialism, $\gamma=-.02, p>.05$, failing to support hypothesis $3 \mathrm{a}$. We decided to drop the non-significant effect of autonomy support and conduct the analysis again since the overall fit of the model could be improved. Results showed that the model fit was better $\chi^{2}=932.67, p=.00(\mathrm{df}=420)$, RMSEA $=.06$ and IFI $=.92$. Consistent with study 1 , examination of the individual parameters revealed a significant positive affect of social comparison on materialism, $\gamma=.47, p<.05$. Similarly, the effects of materialism on positive and negative affect were also significant and in the expected direction, $\beta=-.31, p<.05 ; \beta=.32$, $p<.05$, respectively (see Fig. 2 for the complete model).

\section{Brief discussion study 2}

Study 2 further validated the importance of social comparison as an antecedent of materialism. Results also showed that autonomy support did not predict the endorsement of material values. Lastly, materialism had a significant effect on positive and negative affect. 


\section{General discussion}

In this investigation, we examined the role of social comparison and autonomy support as antecedents of material values and also the affective, cognitive and behavioral consequences of holding this type of values. We found strong support for the role of social comparison as an antecedent of materialism. Social comparison was a robust predictor of the adoption of material values, even stronger than the influence of autonomy support. Why would social comparison be such as important component in the adoption of material values? In order to answer this important question, we need to explain what characterizes the evaluation of material possessions.

\section{Social comparisons and material values}

We compare ourselves with others because it represents a natural way of knowing more about ourselves. Yet a more intriguing question is why social comparison is a key antecedent of materialism. In order to explain this, we have to rely on the difference between the evaluability of experiences vs. material possessions. Evaluability theory suggests that certain attributes or outcomes are easier to evaluate by humans than others (Hsee, Hastie, \& Che, 2008). The theory suggests that certain outcomes are high in evaluability because humans have innate biological scales to judge their desirability. Conversely, other outcomes are low in evaluability because humans do not have innate, but rather socially learned scales to judge their desirability. The desirability of outcomes with low evaluability does not depend only on the characteristics of the outcomes but also on external, socially learned reference points. Examples of outcomes with high evaluability are temperature, stress from work, and social isolation, among others. Income, wealth, and material possessions are examples of outcomes with low evaluability. The desirability of one's material possessions is not only a function of the absolute value they have, but also of what important others possess. It is more comparative in nature. Thus, social comparisons become a driving force to decide and estimate what is desirable to possess. Humans are not naturally equipped to evaluate material possessions, thus the evaluation comes from comparing what we have in relation to others and social comparisons might be particularly relevant in cultures that define the self interdependently such as Mexico (Diaz-Guerrero, 2008).

Our results also showed that the adoption of material values was related to lower levels of positive affect and satisfaction with life and to higher levels of negative affect. Our results are consistent with a wide range of investigation showing the negative consequences of holding material values (Burroughs \& Rindfleisch, 2002; Kasser, 2002). However, if, as some authors have suggested, the adoption of material values is so widespread (Bauman, 2007; Kasser, 2002), what are some of the advantages of holding material values? If it does not lead to higher levels of subjective well-being, what does it lead to?

\section{The possible advantages of endorsing material values}

If materialism is related to lower levels of life satisfaction and positive affect, and higher levels of negative affect, what are some of the advantages of materialism? The answer might come from the conceptualization of situations from evolutionary psychology (Buss, 2009). According to evolutionary psychology, we are designed to pay close attention and act on situations that facilitate or hinder accomplishing one of the main objectives of human life, which is to pass one's genes successfully. In order to accomplish so, people need to be able to choose an appropriate mate. Thus, finding ways to attract a desirable mate is a situation that humans are designed to pay 
attention to and act on it. The chances of having access to an optimal mate increase substantially if one ranks higher in terms of social status, and material possessions are a way of communicating social rank. It follows then that having material possessions might be a way to present oneself as an "attractive" candidate to potential mates by communicating high social status (Rose \& Conlon, 2009).

As suggested earlier, materialism should not only influence consumption related variables, but also behaviors that would facilitate reaching important goals. Our results showed that people with higher levels of materialism were more likely to choose job offers that involved working longer hours and doing more routine activities in order to make more money. Thus, when face with the tradeoff between having more free time or a more exciting job, people with high levels of materialism choose having the chance to make more money. This decision should have a small effect on their well-being since research indicates that income has a small effect on well-being (Rojas, 2009), but should facilitate the acquisition of material possessions, which ironically, does not lead to higher levels of subjective well-being.

Our findings, then, might have implications for marketing and human resources. Emphasizing the importance of acquiring material goods was related to lower levels of satisfaction with life and positive affect and higher levels of negative affect. One line research suggests that consumers should be encourage to buy experiences rather than material goods since experiences lead to higher levels of satisfaction (Dunn, Gilbert, \& Wilson, 2011). Regarding the implications for human resources, research indicates that the quality of reasons for having a job influences job satisfaction. Employees who have more intrinsic reasons for having a job report higher levels of satisfaction than employees who have more extrinsic reasons such as wanting to make more money (Hall \& Las Heras, 2012). Our results showed that participants with higher levels of materialism were more likely to choose jobs with higher salaries but with longer working hours or more routine tasks; jobs likely to lead to lower levels of job satisfaction.

\section{Limitations and future directions}

Our investigation had several limitations. First, we used a correlational design and collected data at one point in time only. Thus, even though we predicted some variables to act as antecedents and others as consequences of material values, we could not actually test for this. Future research should put more emphasis on using longitudinal designs to determine how the tendency to compare one with others increases the importance of adopting material values and how the endorsement of material values might lead to experiencing less positive affect and satisfaction with life. Similarly, longitudinal designs would allow us to examine how material values might influence other important variables such as debt acquisition across time.

Another limitation is that we used a sample of convenience: college students. Students from a private university do not represent well the general population of Mexico. Mexico is a country where income inequalities are considerable (Gasparini \& Lustig, 2011). Thus, future research should assess whether the model of antecedents and consequences of material values tested here would generalize to other segments of the Mexican population. Last, another limitation is that the theoretical models used to guide our investigation were limited in scope. In other words, it would have been ideal to use a model that fully postulated the antecedents and consequences of material values and how cultural variables might have played a role. Hence, we hope that our results can provide empirical evidence for future theory or model development.

In sum, we were able to establish the importance of social comparisons as an antecedent of material values. Given the common occurrence of social comparisons, it is not surprising to see 
the widespread of materialism in today's society (Bauman, 2007). We were also able to establish some of the consequences of holding material values. Materialism was related to lower levels of life satisfaction and positive affect and to higher levels of negative affect. Similarly, materialism also influenced choices of job offers with more hours and more routines activities in order to make more money, lending evidence to the importance of values across different life domains.

\section{References}

Bauman, Z. (2007). Consuming life. Hoboken, NJ: John Wiley \& Sons.

Burroughs, J. E., \& Rindfleisch, A. (2002). Materialism and well-being: A conflicting values perspective. Journal of Consumer Research, 29(3), 348-370. https://doi.org/10.1086/344429

Buunk, B. P., Belmonte, J., Peiró, J. M., Zurriaga, R., \& Gibbons, F. X. (2005). Diferencias individuales en la comparación social: Propiedades de la escala española de orientación hacia la comparación social. Revista Latinoamericana de Psicología, 37, 561-581.

Buss, D. M. (2009). An evolutionary formulation of person-situation interactions. Journal of Research in Personality, 43(2), 241-242. https://doi.org/10.1016/j.jrp.2008.12.019

Deckop, J. R., Jurkiewicz, C. L., \& Giacalone, R. A. (2010). Effects of materialism on work-related personal well-being. Human Relations, 63(7), 1007-1030. https://doi.org/10.1177/0018726709353953

Diaz-Guerrero, R. (2008). Psicología del Mexicano: Descubrimiento de la etnopsicología. México, Ciudad de México: Editorial Trillas.

Diener, E. (1984). Subjective well-being. Psychological Bulletin, 95(1), 542-575. https://doi.org/10.1037//00332909.95.3.542

Diener, E., Emmons, R. A., Larsen, R. J., \& Griffin, S. (1985). The satisfaction with life scale. Journal of Personality Assessment, 49, 71-75. https://doi.org/10.1207/s15327752jpa4901_13

Diener, E., Wirtz, D., Tov, W., Kim-Prieto, C., Choi.F D., Oishi, S., \& Biswas-Diener, R. (2009). New measures of well-being: Flourishing and positive and negative feelings. Social Indicators Research, 39(1), 247-266. https://doi.org/10.1007/s11205-009-9493-y

Dittmar, H., Bond, R., Hurst, M., \& Kasser, T. (2014). The relationship between materialism and personal well-being: A meta-analysis. Journal of Personality and Social psychology, 107(5), 879. https://doi.org/10.1037/a0037409

Domínguez, E., Martín, P., Martín-Albo, J., Núñez, J. L., \& León, J. (2010). Translation and Validation of the Spanish Version of the "Échelle de Satisfaction des Besoins Psychologiques" in the Sports Context. The Spanish Journal of Psychology, 13, 1010-1020. https://doi.org/10.1017/s1138741600002651

Duesenberry, J. (1949). Income, savings and the theory of consumer behavior. Cambridge, MA: Harvard University Press.

Dunn, E. W., Gilbert, D. T., \& Wilson, T. D. (2011). If money doesn't make you happy, then you probably aren't spending it right. Journal of Consumer Psychology, 21, 115-125. https://doi.org/10.1016/j.jcps.2011.02.002

Festinger, L. (1954). A theory of social comparison processes. Human Relations, 7, 117-140.

Gagné, M. (2003). The role of autonomy support and autonomy orientation in prosocial behavior engagement. Motivation and Emotion, 27(3), 199-223.

Gasparini, L., \& Lustig, N. (2011). The rise and fall of income inequality in Latin America. In J. A. Ocampo, \& J. Ros (Eds.), Oxford Handbook of Latin American Economics (pp. 691-714). New York, NY: Oxford University Press.

Gibbons, F. X., \& Buunk, B. P. (1999). Individual differences in social comparison: Development of a scale of social comparison orientation. Journal of Personality and Social Psychology, 76(1), 129-142. https://doi.org/10.1037// 0022-3514.76.1.129

Grougiou, V., \& Moschis, G. P. (2015). Antecedents of young adults' materialistic values. Journal of Consumer Behaviour, 14(2), 115-126. https://doi.org/10.1002/cb.1505

Grouzet, F., Kasser, T., Ahuvia, A., Dols, J., Kim, Y., Lau, S., Ryan, R., Saunders, S., Schmuck, P., \& Sheldon, K. M. (2005). The structure of goal contents across 15 cultures. Journal of Personality and Social Psychology, 89(5), 800-816. https://doi.org/10.1037/0022-3514.89.5.800

Hall, D. T., \& Las Heras, M. (2012). Personal growth through career work. In K. S. Cameron, \& G. M. Spreitzer (Eds.), The Oxford handbook of positive organizational scholarship (pp. 507-518). New York, NY: Oxford University Press.

Hill, S. E., \& Buss, D. M. (2008). The evolutionary psychology of envy. In R. H. Smith (Ed.), Envy: Theory and research (pp. 60-70). New York, NY: Oxford University Press.

Hsee, C. K., Hastie, R., \& Chen, J. (2008). Hedonomics: Bridging decision research with happiness research. Perspectives on Psychological Science, 3(3), 224-243, tps://doi.org/10.1111/j.1745-6924.2008.00076.x 
Kasser, T. (2002). The high price of materialism. Cambridge, MA: MIT Press.

Kasser, T., Ryan, R. M., Couchman, C., \& Sheldon, K. M. (2004). Materialistic values: Their causes and consequences. In T. Kasser, \& A. Kanner (Eds.), Psychology and consumer culture: The struggle for a good life in a materialistic world (pp. 11-28). Washington, DC, US: American Psychological Association.

Kotler, P., \& Keller, K. L. (2013). Dirección de Marketing (13th ed.). México, DF: Pearson.

Lemrová, S., Reiterová, E., Fatěnová, R., Lemr, K., \& Tang, T. L. P. (2014). Money is power: Monetary intelligence-Love of money and temptation of materialism among Czech University students. Journal of Business Ethics, 125(2), 329-348. https://doi.org/10.1007/s10551-013-1915-8

Moriondo, M., Palma, P., Medrano, L. A., \& Murillo, P. (2012). Adaptación de la Escala de Afectividad Positiva y Negativa (PANAS) a la población de adultos de la ciudad de Córdoba: análisis psicométricos preliminares. Universitas Psychologica, 11(1), 187-196.

Mussweiler, T. (2007). Assimilation and contrast as comparison effects: A selective accessibility model. In D. A. Stapel, \& J. Suls (Eds.), Assimilation and contrast in social psychology (pp. 165-185). New York: Psychology Press.

Ogden, H. J., \& Venkat, R. (2001). Social comparison and possessions: Japan vs Canada. Asia Pacific Journal of Marketing and Logistics, 13(2), 72-84. https://doi.org/10.1108/13555850110764775

Pepper, M., Jackson, T., \& Uzzell, D. (2009). An examination of the values that motivate socially conscious and frugal consumer behaviours. International Journal of Consumer Studies, 33(2), 126-136. https://doi.org/10.1111/ j.1470-6431.2009.00753.x

Podoshen, J. F., Li, L., \& Zhang, J. (2010). Materialism and conspicuous consumption in China: A cross-cultural examination. International Journal of Consumer Studies, 35(1), 17-25. https://doi.org/10.1111/j.1470-6431.2010.00930.x

Puente-Díaz, R., \& Cavazos-Arroyo, J. (2015). The influence of personality dimensions on material and frugal values. Anales de Psicología, 31, 37-44. https://doi.org/10.6018/analesps.31.1.167401

Richins, M. L. (2004). The material values scale: Measurement properties and development of a short form. Journal of Consumer Research, 31(1), 209-219. https://doi.org/10.1086/383436

Richins, M. L., \& Dawson, S. (1992). A consumer values orientation for materialism and its measurement: Scale development and validation. Journal of Consumer Research, 19(3), 303-316. https://doi.org/10.1086/209304

Roberts, J. A. (2011). Shiny objects: Why we spend money we don't have in search of happiness we can't buy. New York: Harper One.

Rojas, M. (2009). Economía de la felicidad: Hallazgos relevantes respecto al ingreso y el bienestar. El Trimestre Económico, 76(July-September), 537-573.

Rose, P., \& Colon, K. (2009). Materialism: An evolutionary perspective. In F. Saito (Ed.), Consumer behavior (pp. 185-196). New York: Nova Science Publishers.

Ryan, R. M., \& Deci, E. L. (2002). An overview of self-determination theory: An organismic-dialectical perspective. In E. L. Deci, \& R. M. Ryan (Eds.), Handbook of self-determination research (pp. 3-33). New York: The University of Rochester Press.

Saunders, S. (2001). Fromm's marketing character and Rokeach values. Social Behavior and Personality, 29(2), $191-196$. https://doi.org/10.2224/sbp.2001.29.2.191

Schwartz, S. H. (2005). Basic human values: Their content and structure across countries. In A. Tamayo, \& J. B. Porto (Eds.), Valores e comportamento nas organizações (pp. 21-55). Petrópolis, Brazil: Vozes.

Sheldon, K. M., \& Kasser, T. (2001). Getting older, getting better? Personal strivings and personality development across the life-course. Developmental Psychology, 37(4), 491-501. https://doi.org/10.1037//0012-1649.37.4.491

Srivastava, A., Locke, E. A., \& Bortol, K. M. (2001). Money and subjective well-being: It's not the money, it's the motives. Journal of Personality and Social Psychology, 80(6), 959-971. https://doi.org/10.1037//0022-3514.80.6.959

Uskul, A. K., Oyserman, D., \& Schwarz, N. (2010). Cultural emphasis on honor, modesty or self enhancement: Implications for the survey response process. In J. Harkness, J. Harkness, et al. (Eds.), Survey methods in multinational, multiregional, and multicultural contexts (pp. 191-201). New York: Wiley.

Vazquez, C., Duque, A., \& Hervas, G. (2013). Satisfaction with life scale in a representative sample of Spanish adults: Validation and normative data. Spanish Journal of Psychology, 16, E82. https://doi.org/10.1017/sjp.2013.82

West, S. G., Taylor, A. B., \& Wu, W. (2012). Model fit and model selection in structural equation modeling. In R. H. Hoyle (Ed.), Handbook of structural equation modeling (pp. 209-231). New York: Guilford Press.

Wong, N. Y., \& Ahuvia, A. C. (1998). Personal taste and family face: Luxury consumption in Confucian and Western societies. Psychology \& Marketing, 15(5), 423-441, https://doi.org/10.1002/(sici)1520-6793(199808)15:5<423::aid$\operatorname{mar} 2>3.0 . \operatorname{co} ; 2-9$

Workman, J. E., \& Lee, S. H. (2010). Materialism, fashion consumers and gender: A cross-cultural study. International Journal of Consumer Studies, 35(1), 50-57. https://doi.org/10.1111/j.1470-6431.2010.00935.x 
Xiao, G., \& Kim, J. O. (2009). The investigation of Chinese consumer values, life satisfaction, and consumption behaviors. Psychology \& Marketing, 26(7), 610-624. https://doi.org/10.1002/mar.20291

Zampieri, M., Flores, L., Beuron, T. A., Aitta, L., de Moura, A., \& Lutz, C. (2012). Relação entre materialismo e estilo de consumo: homens e mulheres com comportamento dispare? Contaduría y Administración, 57(1), $185-214$. https://doi.org/10.5585/remark.v11i3.2292 